of syanines in the case of $L$. carinii infestations is attributed to inhibition of the respiratory metabolism. He observes that, in contrast to vertebrates, the metabolic characteristics of invertebrates may vary greatly from species to species, and that morphologically related parasites need not necessarily be sensitive to the same chemotherapeutic agents. He rightly observes that investigations of the biochemical characteristics of pathogenic parasites may lead to the replacement of the present empirical methods by more rational methods of treatment. Lawrence Peters records that certain cyanine dyes had no chemotherapeutic effect on $W$. bancrofti although they proved lethal to $L$. carinii. $\mathrm{He}_{\mathrm{e}}$ believes that this must be attributed, not to the failure of the drug to reach $W$. bancrofti, but to a difference in the meta. bolic characters of the two species.

S. Kushner, L. M. Brancone, Hewitt, W. L. McEwen, Y. SubbaRow, H. W. Stewart, R. J. Turner and J. J. Denton discuss the preparation of the piperazine compounds used in the search for an active filaricide which can be administered orally and is non-metallic. Hewitt, D. E. White, Kushner, W. S. Wallace, Stewart and SubbaRow report on the 'filaricidal' properties of various piperazine compounds, particularly 'Hetrazan', in dogs and cotton rats. Several of the compounds produced immediate and sharp reductions in microfilaria counts in infected cotton rats when administered orally or intraperitoneally; sometimes relapses occurred. 'Hetrazan' was also lethal to the adult worms in dogs and cotton rats. These workers record that they failed to find dead worms at autopsy in some of the treated dogs, and it seems possible that these dogs were infested not with $D$. immitis but with D. acutiuscula, which occur in the subcutis and have been reported from the Canadian lynx (Lynx canadensis). They examined only the heart and lungs for dead worms. B. K. Hamed, R. W. Cunningham, Sybella Halliday, R. E. Vessey, N. N. Yuda, Mary C. Clark and SubbaRow give the structural formula of 'Hetrazan', report on its toxicity for mice, rats, guinea pigs, rabbits, cats and dogs, and cite some of its pharmacological properties.

D. Santiago-Stevenson, J. Oliver-Gonzalez and Hewitt report on the treatment with 'Hetrazan', taken by the mouth, of twenty-six individuals infected with $W$. bancrofti. The dosage varied from $0.5 \mathrm{mgm}$. to $2 \mathrm{mgm}$. per $\mathrm{kgm}$. of body-weight thrice daily for periods varying from three to twenty-two days. For optimum results they suggest a dosage of $2 \mathrm{mgm}$. per $\mathrm{kgm}$. body-weight thrice daily for a period of two to three weeks. There was a rapid disappearance of microfilariæ from the blood, and the development of nodular swellings at certain points of the body, usually infested by the adult worms, is accepted as proof that the compound killed some of the adult worms.

A study of "The Chemotherapy of Filariesis" will reveal that the search for a cure for filarioid infestations in man and his stock cannot be conducted bebind 'iron curtains'. 'The workers in the various fields of science must co-operate and collaborate more and more closely than is usually the case. A better knowledge of the chemical composition and the metabolism of the various helminths parasitizing man, animals and plants may contribute materially towards the discovery of 'cures' which will not only relieve, to some degree, the present world-wide shortages of food, but will also restore normal health to many all over the world.

\section{SOIL THERMODYNAMICS AND ROAD ENGINEERING}

\author{
By J. D. COLEMAN
}

Road Research Laboratory, Harmondsworth, Middlesex

$T$ $\mathrm{HE}$ movement of moisture in soil is of importance to the civil engineer owing to the effect which changes in moistyre content may have on the strength and the volupe of the soil. In the case of roads, both the stability and the riding qualities of the surface gre involved.

The hermodynamics of the moisture contained in hygroscopic materials such as paper, tobacco and textiles has received considerable attention, and much has already been done, particularly by agricultural scientists, in applying this work to soils. A fundamental approach on these lines to the many problems associated with the transfer of moisture in road foundations is at present being made at the Road Research Laboratory.

The potential causing the migration of soil water may be regarded either as a hydraulic pressure or a vapour pressure gradient. Movements cease only when suction and vapour pressure conditions are in equilibrium with the acting gravitational field under the prevailing temperature conditions.

The curvature of each of the air/water interfaces in the soil pores is a function of the pressure change through the meniscus and of the relative humidity at the interface. The relationship between relative humidity is given to a close degree of approximation by the well-knorm Kelvin equation, which may be written,

$$
\frac{\rho \cdot R \cdot \theta}{M} \cdot \log _{e} \frac{H}{100}=-\frac{2 T}{r} .
$$

The actual change in pressure through the meniscus, p.g.h $=2 T / r$, can be expressed in terms of Schofield's $p F^{\prime}$ function,

$$
p F=\log _{10} h=\log _{10} \frac{2 T}{\rho \cdot r \cdot g} .
$$

Equations (1) and (2) have been used by Schofield and others in the determination of the $p F$ of soils at low moisture contents.

In the soil itself, the curvature of the air/water interfaces depends on the moisture content and on certain characteristics of the soil solids, the chief of which appears to be the particle-size distribution. It follows that the suction/moisture content and the relative humidity/moisture content relationships depend on soil type; and, in fact, the moisture contents of two dissimilar soils in moisture equilibrium may be greatly different. In road construction, where it is common on clay soils to use a stable sandy soil to form part of the road foundation, the suction/moisture content relationships are useful in estimating the equilibrium moisture (and strength) conditions.

Road foundations are subjected to both the daily and the yearly temperature cycles. It is therefore necessary to ascertain the effect of temperature on the suction and humidity relationships. The variation of the density of the soil water with temperature causes only a second-order variation in the radii of the air/water interfaces. Neglecting this variation, it follows from (2) that at two temperatures $\theta_{1}$ and $\theta_{2}$,

$p F_{\theta_{1}}-p F_{\theta_{2}}=$

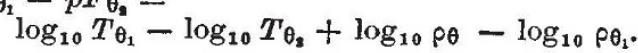




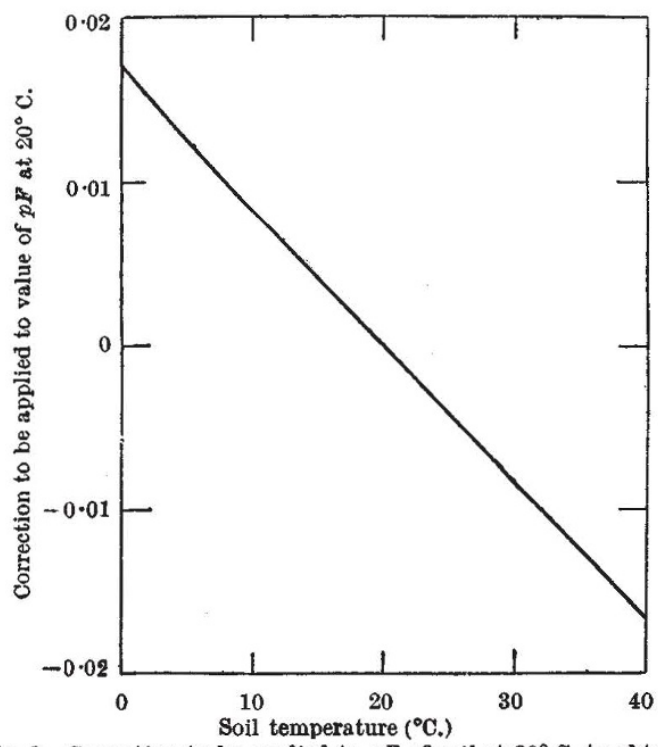

Fig. 1. Correction to be applied to $p F$ of soil at $20^{\circ} \mathrm{C}$. to obtain $p F$ at other temperatures

Fig. 1, obtained from this equation, shows how small the suction difference associated with tempera. ture gradients will be. The correspondingly small variation with temperature of the relative humidity of soil water follows from equation (1), since

$$
\frac{\log _{e} H_{\theta_{1}} / 100}{\log _{e} H_{\theta_{2}} / 100}=\frac{T_{\theta_{1}}}{T_{\theta_{2}}} \cdot \frac{\theta_{2}}{\theta_{1}} \cdot \frac{\rho_{\theta_{2}}}{\rho_{\theta_{1}}} \text {. }
$$

This relationship is used to obtain Fig. 2.

The small change in relative humidity with temperature indicates that the vapour pressure of soil water varies with temperature in a manner similar to that of free water. A family of typical vapour pressure/temperature/moisture content curves is shown in Fig. 3. It follows that considerable vapour pressure gradients may be set up by comparatively small temperature differences. Further, since the relative humidity of soil water is sensibly different from 100 per cent only at moisture contents lower than those of interest to the road engineer, the following two conclusions can be reached :

(1) Differences in soil moisture content under the road will cause suction gradients virtually unaccom-

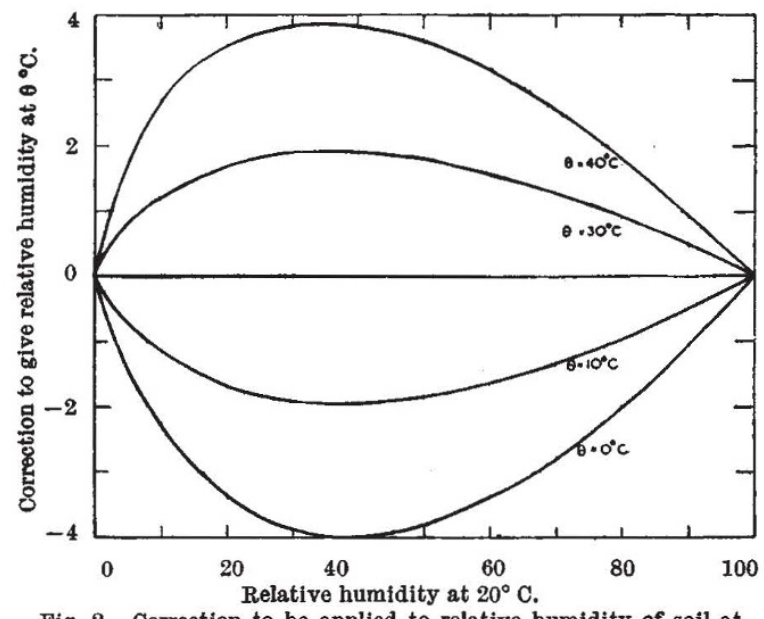

Fig. 2. Correction to be applied to relative humidity of soil at $20^{\circ} \mathrm{C}$. to obtain relative humidity at other temperatures panied by vapour pressure gradients, and transfer will normally be in the liquid phase.

(2) Differences in temperature will cause vapour pressure gradients but not appreciable suction gradients, and transfer will normally be in the vapour phase.

Interesting confirmation of these conclusions has been obtained in this Laboratory and from practical observations. The severe drought in 1947 caused an abnormal reduction in the moisture content of road verges. Transfer of moisture in the liquid phase resulted in severe settlement and cracking on a number of roads built on heavy clays. In some parts of the world, seasonal temperature gradients are such as to cause the upward migration of water from considerable depths. Reports have been received from arid regions of Califormia of vegetation confined solely to the verges of roads where evapora. tion of moisture brought to the surface was prevented by the impermeable road metal.

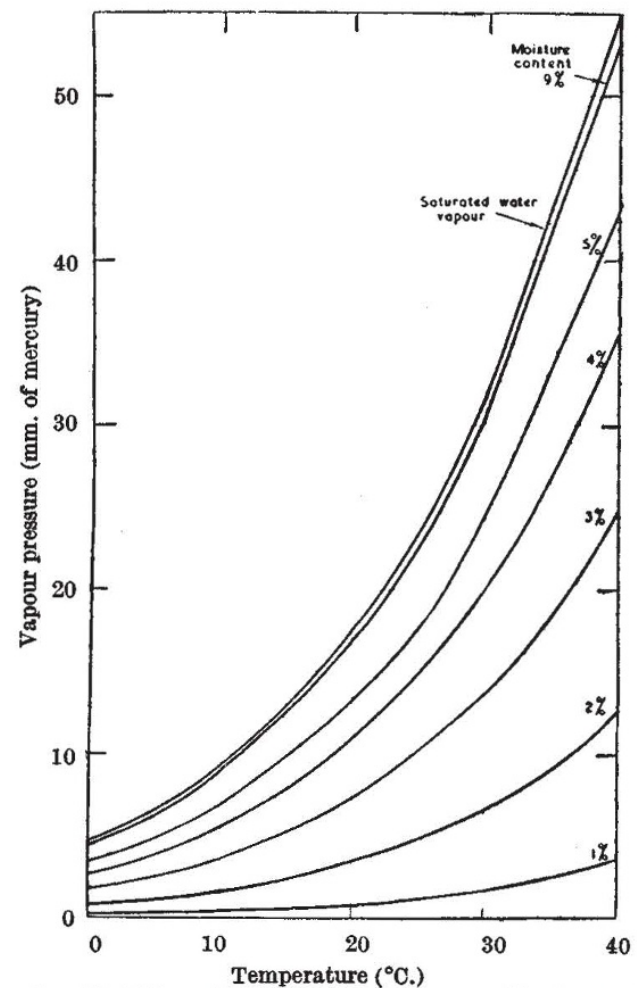

Fig. 3. Variation of soil vapour pressure with temperature

The problem of moisture transfer also involves consideration of the heat of wetting, the latent and specific heats of the soil water and the effect of temperature on each of these quantities. Detailed consideration has been given so far only to the heat of wetting. The differential heat of wetting of a hygroscopic material is obtained by Shorter $^{2}$ as

$$
Q=-\frac{R \theta^{2}}{J M} \cdot \frac{\partial}{\partial \theta}\left[\log _{e} \frac{H}{100}\right]
$$

Using the differential of equation (1)

$$
Q=\frac{-R \theta^{2}}{J M} \cdot\left[\frac{1}{T} \cdot \frac{\partial T}{\partial \theta}-\frac{1}{\theta}-\frac{1}{\rho} \cdot \frac{\partial \rho}{\partial \theta}\right] \log _{e} \frac{H}{100} .
$$

Equation (6) enables the differential heat of wetting to be calculated at any given temperature. At tem. peratures $\theta_{1}$ and $\theta_{2}$, equations (6) and (4) give 


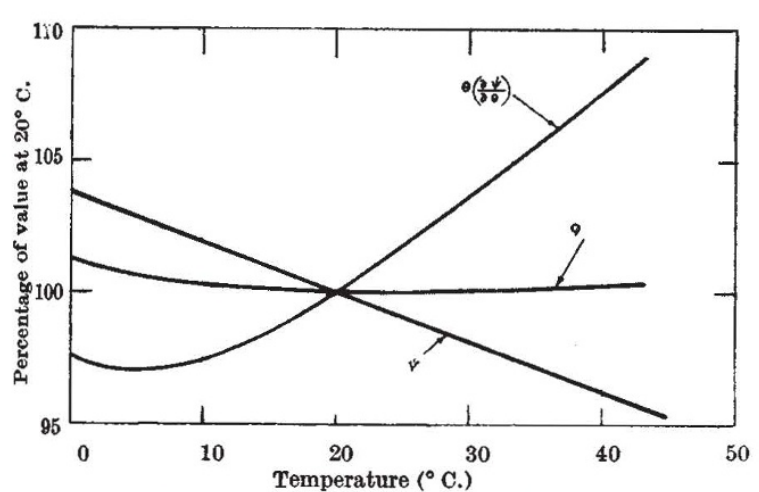

Fig. 4. Temperature variation of capillary potential, $\psi$, heat of wetting and bound energy, $\theta(\partial \psi / \partial \theta)$

$$
Q_{\theta_{1}}=Q_{\theta_{3}} \frac{\left[\frac{1}{T_{\theta_{1}}}\left(\begin{array}{c}
\partial T \\
\partial \theta
\end{array}\right)_{\theta_{1}}-\frac{1}{\theta_{1}}-\frac{1}{\rho_{\theta_{1}}}\left(\frac{\partial \rho}{\partial \theta}\right)_{\theta_{1}}\right] \theta_{1} \cdot T_{\theta_{1}} \rho_{\theta_{2}}}{\left[\frac{1}{T_{\theta_{2}}^{\prime}}\left(\frac{\partial T}{\partial \theta}\right)_{\theta_{2}}-\frac{1}{\theta_{2}}-\frac{1}{\rho_{\theta_{2}}}\left(\frac{\partial \rho}{\partial \theta}\right)_{\theta_{2}}\right] \theta_{2} \cdot T_{\theta_{2}} \rho_{\theta_{1}}} .
$$

Equation (5) can be written in the form

$$
Q=\psi-\theta d \psi / d \theta
$$

where $\psi$, Buckingham's capillary potential, $-g h$, is given by

$$
\psi=\frac{R \cdot \theta}{M} \cdot \log _{e} \frac{H}{100} .
$$

In Fig. 4 the temperature variation of $Q$ and each of its components $\psi$ and $\theta . \partial \psi / \partial \theta$ is given. These curves are based on equation (7). The quantity $\partial T / \partial \theta$ was obtained from accurate surface tension data.

- Further investigations are in hand, and it is hoped to publish a fuller account, including experimental results, in due course. The work is being undertaken as part of the programme of the Road Research Board, and the present note is published with the consent of the Director of Road Research.

${ }^{1}$ Schofield, R. K., Trans. 3rd Inter. Cong. Soil Sci., 2 (1935). 'Shorter, S. A., J. Tex. Inst., 15 (1924).

'Buckingham, E., U.S. Dept. Agric., Bur. Soils, Bull. No. 38 (1907).

$$
116
$$

\section{DEVELOPMENTS IN PICTURE TELEGRAPHY}

$\mathrm{T}$ HE transpaissto of pictures by land-line over various distemes Apreen the subject of experimental defelon ment since the earliest days of telegraphipogrmunication; and the techniques involved haye bepn adapted similarly for transmission or raving over radio links. Amid the excitement of othor applications in recent years, such as broadcasting, radar and television, the very advanced stage which has been attained by picture or facsimile telegraphy, as the technique is termed, is apt to be overlooked. Many systems have been suggested and experimented with; but they have had a common besis in that the picture to be transmitted is placed on a revolving drum and scanned with a suitable source of light and optical system. The variations in light intensity reflected or scattered by the varying tones of the picture are converted into a fluctuating electric current through the agency of a photoelectric cell. 'The resulting signals are transmitted by line or radio to the receiving station, where they may be converted by a current-sensitive oscillograph into light variations which record the picture on suitable photographic paper. Alternatively, the electric currents are made to reproduce the picture by an electrochemical process. In either case, the recording paper is mounted on a drum which is maintained in rotation synchronously with that at the transmitting station.

This technique of the transmission of pictures by telegraphy is used to a large and successful extent by the Press to obtain quickly the illustrations which accompany accounts of topical events all over the world. But there are other applications in industry and the public service; and one of these, the transmission of fingerprints by radio, has been referred to in Nature, 158, 525 (1946).

The name of Muirhead has been associated for more than a century with the development of instru. ments used in various branches of telecommunications, including in recent years the very successful production of phototelegraphic equipment. At the recent symposium held by the Scientific Instrument Manufacturers Association of Great Britain, Ltd., a paper entitled "Some Developments in Picture Telegraphy" was presented by Mr. J. Bell, of Muirhead and Co., Ltd., who have also supplied some technical literature and bulletins giving further details of the equipment. For some time now a number of the larger newspapers have operated their own picture transmission circuits comprising telephone lines linking their editorial offices with various population centres; and Muirhead-Jarvis picturetelegraph transmitting and receiving equipment is now in operation in a large number of newspaper offices in Great Britain and northern Europe. The apparatus has been designed to conform with the requirements laid down by the Comité Consultatif International Télégraphique (C.C.I.T.), and it may therefore be worked with the principal phototelegraphic services abroad which conform to the same standards.

An amplitude-modulated form of transmission is used over wire circuits, while for radio links the principle of sub-carrier frequency-modulation is used, thereby ensuring that the signals representing the tone values of the picture are not greatly affected by fading and other disturbances of the radiofrequency carrier-wave during transmission. The picture transmission band is from 300 to 2,300 cycles per second and is thus easily within the scope of a normal telephone channel.

The standard equipment installed at the terminal fixed stations uses drum speeds of either 1 or 2 revolutions per second, and the picture is scanned at either 100 or 150 lines per inch $(3.9$ or 5.9 lines per $\mathrm{mm}$.) for all normal requirements. Under these conditions, a picture of size $10 \frac{1}{2} \mathrm{in}$. by $10 \mathrm{in}$. $(267 \mathrm{~mm}$. by $254 \mathrm{~mm}$.) can be transmitted in $16 \mathrm{~min}$. $40 \mathrm{sec}$. and $25 \mathrm{~min}$. respectively. For super-quality work, scanning at 300 lines per inch (11.8 lines per mm.) can bo used, and the results obtained under these conditions are so accurate in detajl as to render it difficult to distinguish the received picture from the original.

The use of normal telephone channels for the communication of news direct from the scene of the event has been followed by a demand for com. parable facilities for the transmission of pictures, and the Muirhead-Belin portable transmitter has been developed to meet this demand. This equipment 